\title{
Review on Globalization and Importance of Strategic Human Resource Management
}

\author{
Dr. Bandar Khalaf Alharthey \\ Arab East Colleges, Riyadh, Kingdom of Saudi Arabia \\ P.O. Box: 53354
}

\begin{abstract}
Strategic human resource management (SHRM) is the main concern of the managers who are expanding their business at global level. In the current era, recognition of value of the human factor is emphasized by the managers to align business strategy and HR policies. The main purpose of the article is to explore facts about the impact of globalization on HRM with special reference to SHRM. In order to assess these aspects, implications of globalization and SHRM will be analyzed and global orientation of HR professionals will be assessed, so that a deep insight about the importance of SHRM can be developed.
\end{abstract}

Key words: Human resource management, strategic human resource management, cultural differences, globalization, organizational drivers.

\section{Introduction}

In the current business scenario, human resource management (HRM) policies and practices are essential to be integrated optimally for becoming successful in the global business environment. The wave of globalization has revolutionized the trends and challenges of HRM, which are required to be handled effectively for managing the diverse workforce. Strategic human resource management (SHRM) is one of the most important aspects of HRM practices that facilitates the implementation of effective HR policies to meet the requirements of the employees, while proceeding ahead to accomplish the organizational goals (Mathis and Jackson 2008).

SHRM is significant towards the assurance of long term success of the business organizations in the global market place. Since globalization has an influence on the HRM practices of the organizations, so it is essential to homogenize the strategies and processes of the organizations. Globalization has directed alterations in the HR approach of the organizations. In this concern, the practice of SHRM is beneficial for the organizations to take proactive measures for improving the efficiency of the employees (Deb 2006). Therefore, the main purpose of the study is to explore the impact of globalization on HRM with special reference to SHRM. With respect to this, different literary sources will be analyzed. It has been observed that today's business environment needs the establishment of strategies approach to the management of HRM for coping with the global forces.

\section{Literature Review}

The method review of historical studies is taken into account for the assessment of the impact of globalization on HRM. The significance of SHRM in the globalize market is analyzed to emphasize on the need of SHRM for the organizations. It has gained attention with the advent of globalization and the growth of the organizations to expand their presence in new markets. SHRM facilitates the managers with the global orientation to manage workforce and comply with the new trends. The wave of globalization has opened up opportunities for the HR managers to adopt the strategic approach to HRM, so that diverse workforce across the world can be integrated optimally. In the next section, the diverse aspects of globalization and SHRM are analyzed. 


\section{Globalization and SHRM}

Globalization has become a major component of the business framework of the organizations. It symbolizes the structural transformation of the business practices accompanied by free exchange of HR and technology beyond the regional boundaries. Human factor is important and taken into the account by the businesses for sustaining their growth in the new era of globalization. Cesyniene (2008) emphasizes that HRM is an essential segment of the business to be managed with great care while adopting the expansion strategy in the operations. In this concern, it is vital to establish an effective association between the strategy framework and HRM that is applicable at both the national and international level (Festing 1997).

Key issues, which are confronted by the organizations in global marketplace, are related to the size and cultural differences that are required to be considered for making investment in the human resource development. Global competitiveness has to be improved and employees are required to be empowered by making centralization of the HR practices. Some issues are related to the staffing policies and training of employees for stimulating creativity and innovation in the business operations. The challenges that have to be recognized by the HR professionals while working in global market are related to the consideration of performance appraisals, compensation packages, training and development, and labor relations in accordance with the employment rules and regulations (Gachoka 2008).

SHRM is a proactive approach to manage diverse workforce that has a significant influence on the corporate strategy of the multinational corporations. It basically emphasizes on the integration and adaptation across the defined hierarchy levels. Effective HR measures have to be adopted by the organizations for coping in the competitive business environment. The approach of SHRM is an inherent segment of the organizations success in attaining the defined mission and business strategy. This practice is aimed at establishing a link between the key workforce and strategic goals, which are important for sustaining improvements in the business performance and establishment of culture that promotes the drive for innovation and flexibility (Inyang 2010).

In the framework of SHRM, human resource is recognized as strategic associates of the organization, which play an important role in the definition of the corporate strategies and HR strategies. It is essential that SHRM should be focused towards performing the environmental scanning, availability of competitive workforce and assessing the impact of skills of employees on the capability of the organization. SHRM practices are related to the assessment of the organizational performance and the extent of alignment between the workforce and organizational strategy, so that competitive edge can be gained (Karadjova-Stoev and Mujtaba 2009).

\section{Implications of Globalization on SHRM Practices}

Globalization needs greater attention of the HR professionals for establishing their operations in the different cultural settings. In order to harmonize the global operations successfully, it is necessary for the HR managers to focus on the balancing of the complementary forces, so that centralization and teamwork can be maximized in the organization (Kim 1999). The framework of complementary forces is represented below. Cultural diversity has to be adopted within the business operations to manage and lead the people in an organized manner. Cross-cultural dimensions of the functional aspects of HRM are also significant for meeting the emerging requirements of the key workforce. 


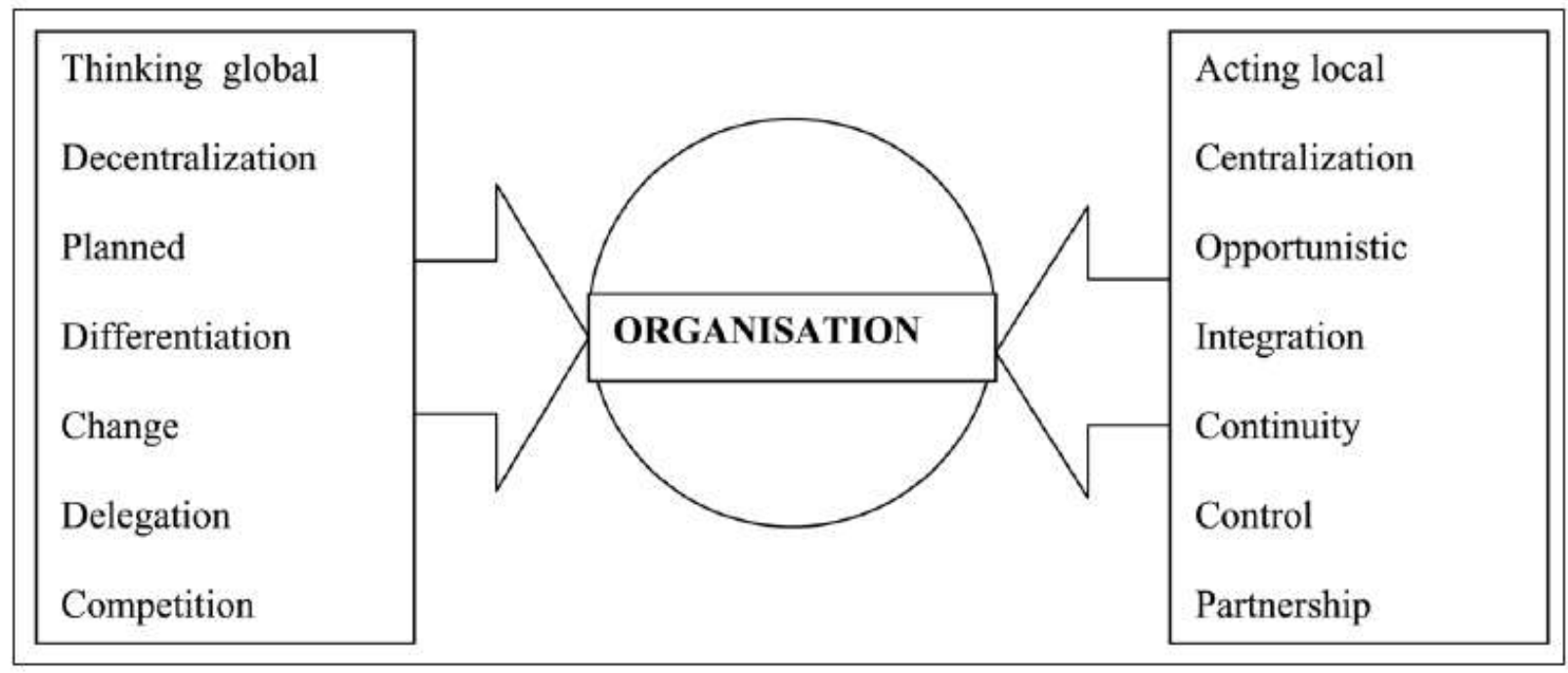

Figure 1: Complementary forces that has to be balanced by managers in global organizations (Cesyniene 2008)

SHRM practices are vital for the alignment and integration of the diverse workforce acquired through the expansion of business globally. With the assistance of the adoption of SHRM practices, the skills and professional competence of the HR managers get developed. It is helpful in addressing the complex nature of the management of people on the basis of the consideration of valuable resource. Through this approach, HR professionals become capable in identifying the external and internal factors that are required to be analyzed and interpreted carefully to develop integrative framework (Mathis and Jackson 2008). Impact of SHRM on the organizations can be managed by establishing best fit between the policy framework and strategies, which can be analyzed from the below represented figure:

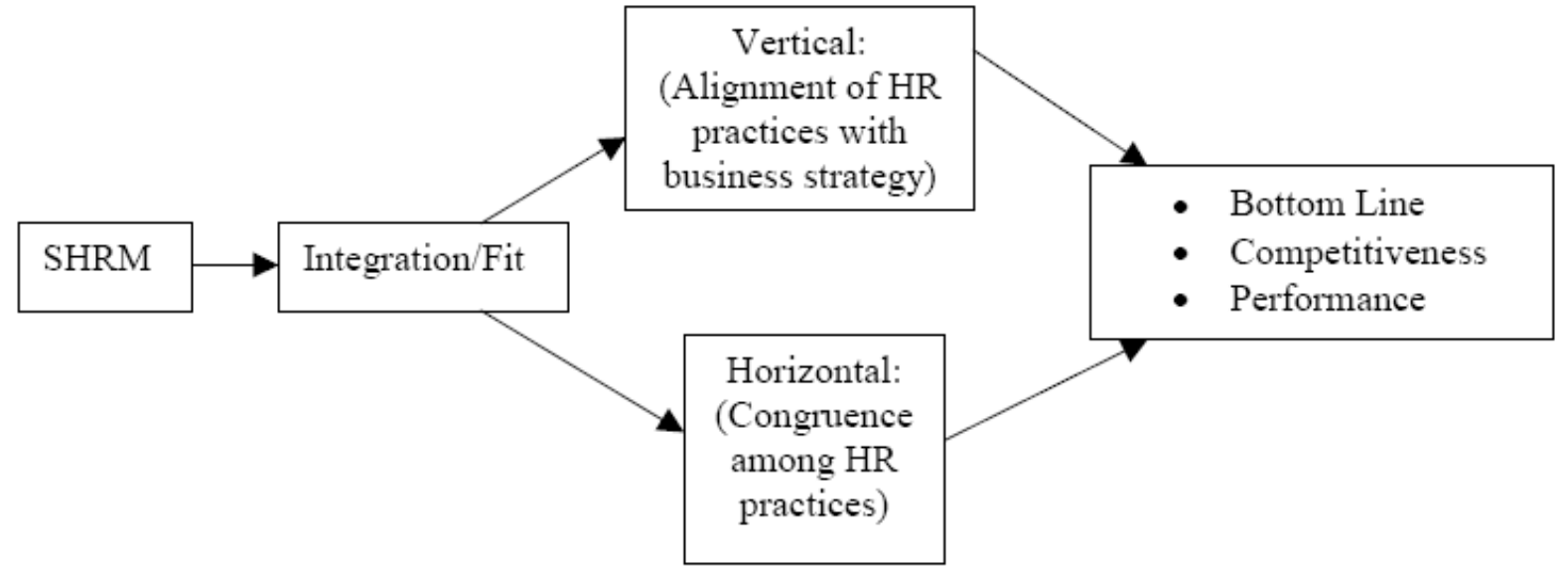

Figure 2: Best fit between HR practices (Inyang 2010)

Some of the external factors that require consideration are industry characteristics, nature of competitors, country/ regional environment and technology. These aspects are helpful in aligning the strategies to manage diverse workforce in terms of the social, cultural and legal norms of the target market. Some of the internal factors that are required to be assessed by the HR professionals are organizational structure, competitive strategy, global experience and global orientation. With the assistance of analysis of these factors, business and HR strategy can be formulated and implemented accordingly. SHRM approach has transformed the orientation of the organizations towards the utilization of key workforce for the management of the business transactions at global level (Karadjova-Stoev and Mujtaba 2009).

\section{Global orientation of HR professionals}

While working at global level, HR policies and procedures adopted by the organizations have to be strategically defined. Staffing policy has a great impact on the business operations and HR professionals require focusing on the integration of the available workforce. Cultural awareness and diversity management are the major aspects that affect the managerial prospects of HRM in the organizations. The orientation of the HR professionals has to be global for the sustenance of the growth prospects of the organization and expansion of the operations in new markets (Brewster, et al. 2005). 
Standardization of the HR practices to manage localized operations provides assistance to the managers in accomplishing sustainable competitive advantage. Business organizations focus on implementing their own practices in the host country or follow local HR practices to unite their operations and become more competitive globally (Krninska 2002). In the fast food franchises, like McDonald's Burger King, Pizza Hut, Domino's Pizza, etc. polycentric approach of HR management is followed by the professionals for emphasizing on the market requirements in a competitive manner. Managers positioned in the host country manage the operations of these franchises in their own way to gain competitive advantage (Karadjova-Stoev and Mujtaba 2009).

Paradigm shift in the HR practices of the organizations with respect to SHRM is beneficial in focusing on the performance output and assessment of the HR policies as solutions to the issues of business. SHRM is helpful for the HR managers in making systematic amendments in the practices and emphasizing on the consistency within the organizational activities. Planned perspective is followed to integrate the organizational goals and HR policy framework that has to be adopted at global level. Global orientation to make the HR policies flexible and stimulating innovation in the organizational practices is helpful in adding value to the business proposition (Inyang 2010).

\section{Results}

Business aspects of the organizations are highly influenced by globalization and diversity in cultural setting. The key challenge in front of the HR managers to organize and integrate international operations is related to the harmonization of the complementary forces, so that the concept of soft HRM can be followed effectively. This approach is beneficial in emphasizing on the fulfillment of the requirements of the employees and attaining potential benefits to gain competitive advantage. It has been found that the wave of globalization has transformed the approach and orientation of the HR managers about the management of the organizational performance and individual behavior (Gachoka 2008).

With the assistance of the SHRM practices, more emphasis is laid on the implementation of value-added business responsibilities, so that the best fit, as well as, alignment between the business strategy and HR practices can be established. It is a systematic approach for adding value to the strength of the human capital by recognizing the importance of organizational performance as compared to the individual outcomes. SHRM framework is helpful in establishing best fit between the HR and business strategies to attain competitive edge and lead the business towards success (Festing 1997). Strategic positioning of the valuable human capital is essential to be aligned in compliance to the strategies goals for ensuring growth.

\section{Discussion}

SHRM practices are highly advantageous for the business organizations in gaining accession to well aligned and committed workforce. Key organizational drivers are essential to be taken into account while emphasizing on the expansion of the business globally and centralization of the performance outputs. Knowledge transfer among the diverse workforce is helpful for the HR managers in emphasizing on the core business processes and formulation of strategies relationships with the employees. Organizational drivers based global HR model as identified by Brewster and his associates (2005) is represented below, which is helpful in analyzing the alignment of the HR processes and organizational outcomes. 


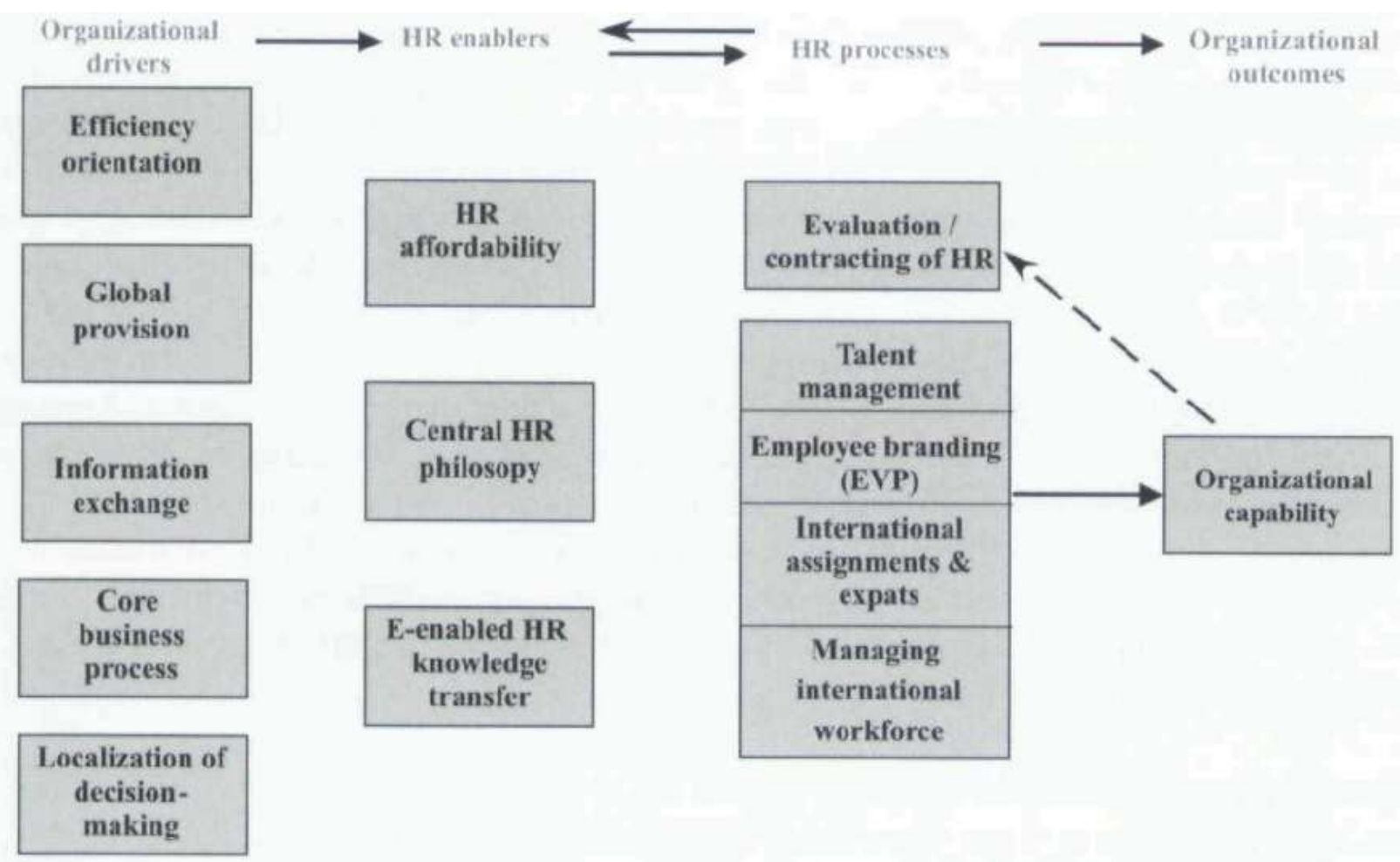

Figure 3: Global HR Model (Brewster, et al. 2005)

The model is helpful in emphasizing on the relative proposition of the diverse organizational drivers that are guiding souls for the alignment of the employees and growth of the businesses. With the assistance of the adoption of SHRM practices, business performance can be headed towards accomplishing success in the globalize marketplace (Kim 1999). It is essential for the HR managers of multinational corporations to demonstrate their competence for managing the challenges of globalization. In the current era of globalization, it is necessary for the business organizations to emphasize on the human factor, so that long term success and growth can be ensured.

\section{Conclusion}

It can be inferred from the above discussion that recognition of the value of the human capital is essential for the business organizations to approach their operations in the global marketplace. HR managers have to lay emphasis on the integration and alignment of the diverse workforce on the basis of the consideration of their needs and cultural differences. Strategic approach to HRM is beneficial for the managers in valuing the growth prospects of the organizations and sustaining competitive workforce to increase the competence level of the organization at global level. 


\section{References}

[1] Brewster, C. et al. 2005. Towards a new model of globalizing HRM. International Journal of Human Resource Management 16, pp. 949-970.

[2] Cesyniene, R. 2008. Globalization and Human Resource Management. Economica 82, pp. 41-56.

[3] Deb, T. 2006. Strategic Approach to Human Resource Management. Atlantic Publishers \& Distributors.

[4] Festing, M. 1997. International human resource management strategies in multinational corporations: Theoretical assumptions and empirical evidence from German firms. Management International Review.

[5] Gachoka, H. 2008. Impact of Globalization on the Human Resource Management Function in Developing Countries: A Case Study of Kenya Public Corporation. KCA Journal of Business Management 1(1).

[6] Inyang, B.J. 2010. Strategic Human Resource Management (SHRM): A Paradigm Shift for Achieving Sustained Competitive Advantage in Organization. International Bulletin of Business Administration (7), pp. 23-36.

[7] Karadjova-Stoev, G. and Mujtaba, B.G. 2009. Strategic Human Resource Management and Global Expansion Lessons from the Euro Disney Challenges in France. International Business \& Economics Research Journal 8(1), pp. 69-78.

[8] Kim, P.S. 1999. Globalization of Human Resource Management: A Cross-Cultural perspective for the Public Sector. Public Personnel Management 28.

[9] Krninska, R. 2002. Globalization, human resources and the increase of their potential in relation to sustainable development in regions. Agricultural Economics 48(3), pp. 126-129.

[10] Mathis, R.L. and Jackson, J.H. 2008. Human Resource Management. $12^{\text {th }}$ ed. Cengage Learning. 